\title{
Multiple origins and genetic diversity in the newly arisen allopolyploid species, Senecio cambrensis Rosser (Compositae)
}

\author{
PAUL A. ASHTON \& RICHARD J. ABBOTT \\ Department of Biology and Preclinical Medicine, Sir Harold Mitchell Building, University of St Andrews, St Andrews, \\ Fife KY16 9 TH, Scotland, UK
}

\begin{abstract}
A survey of allozyme variation was conducted in populations of the newly arisen allopolyploid species Senecio cambrensis and its two parental species $S$. vulgaris and $S$. squalidus sampled from the three locations in Britain where $S$. cambrensis is known to occur, i.e. at Wrexham and Mochdre in Wales, and Edinburgh in Scotland. Electrophoretic variation at the Acp-1 and $\alpha$ Est-1 loci provided strong evidence of separate origins of $S$. cambrensis in Wales and Edinburgh. The possibility of two additional independent origins of the species in Wales was indicated by the variation pattern at the Aat-3 locus, although this variation could be explained as a result of segregation from a fixed heterozygote (representative of a single origin) following pairing between homoeologous chromosomes, as could the pattern of variation recorded at the $\beta E s t-3$ locus. For no enzyme system were additional allozymes found in $S$. cambrensis which were not present in one of the respective parents. The ability of $S$. cambrensis to originate at different locations and to generate genetic diversity following recombination between its parental genomes, might act in favour of its establishment and diversification in Britain.
\end{abstract}

Keywords: allopolyploidy, Compositae, genetic diversity, isozyme variation, Senecio cambrensis, speciation.

\section{Introduction}

The origin of new plant species via allopolyploidy is now a well-documented phenomenon. Within the past 110 years, four new allopolyploid species are known to have originated in the wild; two in North America, Tragopogon mirus Ownbey and T. miscellus Ownbey (Ownbey, 1950; Roose \& Gottlieb, 1976), and two in Britain, Spartina anglica C. E. Hubbard (Huskins, 1931; Marchant, 1963, 1967, 1968; Raybould et al., 1991a) and Senecio cambrensis Rosser (Rosser, 1955; Abbott et al., 1983). The discovery of these new species soon after their origin has presented an excellent opportunity for detailed analysis of the process of allopolyploidy, now regarded as a mode of speciation of great significance in the plant kingdom (Lewis, 1980; Stace, 1987). Important questions concern whether particular allopolyploids have originated once or several times, whether novel characters are present in newly arisen allopolyploids, and whether allopolyploids generate genetic variation during the early period of establishment.
Senecio cambrensis is an allohexaploid species $(2 n=60)$ formed after hybridization between $S$. vulgaris L. $(2 n=40)$ and $S$. squalidus L. $(2 n=20)$ (Fig. $1)$. The hybrid between these plants is a sterile triploid which can give rise to the fertile allohexaploid by a doubling of the chromosome complement. Harland (in Rosser, 1955) and Weir \& Ingram (1980) have produced the allohexaploid artificially by treating synthetic hybrids with colchicine. The resulting plants closely resembled wild ones, being intermediate between the parents in many characters but with larger achenes, and pollen with four pores rather than three. Synthesized and wild plants are self-compatible and show high levels of seed set when left to self. The species was first described from the wild by Rosser (1955) following its discovery in 1948 by H. E. Green at Cefn-yBedd, near Wrexham, Denbighshire, North Wales. In North Wales, contact between the parental species did not occur until the early part of the present century (approximately 1910) following the escape and spread of $S$. squalidus, an introduced species, from the Oxford Botanic Garden (Kent, 1956, 1963). It is concluded 


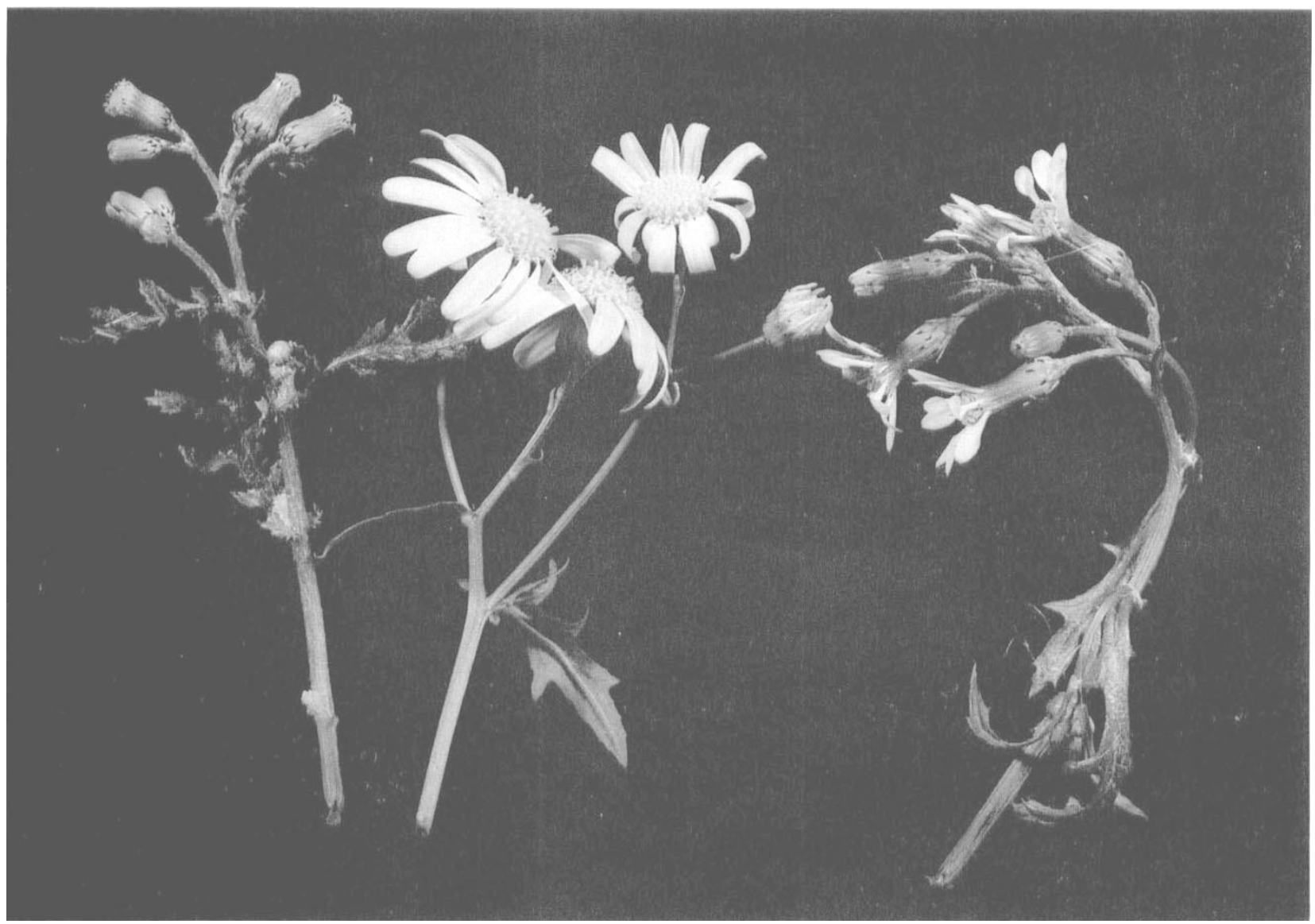

Fig. 1 Flower heads of the allohexaploid Senecio cambrensis (right) and its parental species S. squalidus (centre) and S. vulgaris var. vulgaris (left).

that $S$. cambrensis originated in North Wales sometime between 1910 and 1948.

In Wales, $S$. cambrensis is now common on roadside verges, walls and wasteground in Wrexham, and the villages and small towns nearby (Ingram \& Noltie, 1991). Away from the area, populations of $S$. cambrensis have been discovered first at Mochdre, near Colwyn Bay, North Wales in 1966 (Brummitt, 1971) and more recently at Leith in Edinburgh, Scotland in 1982 (Abbott et al., 1983). These populations are considered to have formed at progressively later dates than those in the Wrexham area, most probably after $S$. squalidus had spread to and become established at the respective locations. For example, although cultivated material of $S$. squalidus had been raised in Edinburgh before 1950, the species was not reported as established in the city until after this date (Kent, 1955; Crisp, 1972). The triploid hybrid $S$. vulgaris $\times S$. squalidus was first collected from the wild in Edinburgh in 1974 where it occurred on demolition and redevelopment sites at low frequency in Leith (Ingram et al., 1980; Marshall \& Abbott, 1980). The first speci- men of $S$. cambrensis was also collected in 1974 from the Leith area of Edinburgh but was not identified as such until 1983, having initially been mistaken to be $S$. vulgaris $\times$ S. squalidus (Abbott et al., 1983).

In view of the distance between North Wales and Edinburgh, and the absence of $S$. cambrensis from intermediate sites, the possibility is raised that the Welsh and Edinburgh populations are derived from two separate origins of the species in Britain this century. If this is so, the Edinburgh variant is likely to have originated not more than 40 years ago and most probably within the past 20 years. Of additional interest is the possibility that the population at Mochdre, which is located approximately $40 \mathrm{~km}$ from Wrexham, is also the product of a separate origin. With this in mind, an electrophoretic survey of isozyme variation in $S$. cambrensis and its parental species $S$. vulgaris and $S$. squalidus was conducted on material sampled from the three geographically disjunct localities where $S$. cambrensis has been found in Britain, i.e. Wrexham, Mochdre and Edinburgh. The objectives of the study were: (i) to determine if there has been one or several 
origins of S. cambrensis in Britain; and (ii) to detect how much genetic variation is present in the different populations of $S$. cambrensis and whether this is related to length of time since origin.

\section{Materials and methods}

Seeds (achenes) were collected from plants of $S$. cambrensis, S. vulgaris (both radiate var. hibernicus, and non-radiate var. vulgaris forms) and $S$. squalidus that grew in populations at Edinburgh (Leith), Mochdre (North Wales) and at four sites near Wrexham (North Wales), namely at Brymbo, Ffrith, Rhostyllen and Southsea. The locations of populations, site descriptions, number of plants sampled and collection dates are listed in Table 1. After germination, seedlings were grown in a greenhouse for between 6 and 10 weeks before they were assayed. One offspring from each mother plant sampled per population was examined.

Horizontal starch gel electrophoresis was conducted on crude protein extracts of leaf or flower bud tissue. The following enzymes were assayed: acid phosphatase (ACP), aspartate aminotransferase (AAT), $\alpha$-esterase $(\alpha$ EST), $\beta$-esterase ( $\beta$ EST), glucose- 6 -phosphate dehydrogenase (G-6PD), glutamate dehydrogenase
(GDH), glyceraldehyde-3-phosphate dehydrogenase (G-3PD), malate dehydrogenase (MDH), malic enzyme (ME), peroxidase (PER), 6-phosphogluconate dehydrogenase (6-PGD), phosphoglucomutase (PGM), phosphoglucose isomerase (PGI). Details of electrophoretic and staining procedures are given in Ashton (1990) and are available from R. J. Abbott on request.

Where two or more isozymes of a given enzyme were resolved on a gel and were considered to be the products of genes at different loci, the locus coding for the most anodally migrating protein was designated 1 , the next 2 , etc. Similarly, at each polymorphic locus the allele encoding the most anodally migrating allozyme was designated $a$, the next $b$, and so on.

\section{Results and discussion}

The isozyme banding patterns for eight enzyme systems (G-6PD, G-3PD, MDH, ME, PER, PGM, 6-PGD and PGI) were identical over all individuals of $S$. cambrensis, $S$. vulgaris and $S$. squalidus surveyed (Ashton, 1990). The electrophoretic phenotypes for those enzymes which showed polymorphism, i.e. ACP$1, \alpha \mathrm{EST}-1, \beta \mathrm{EST}-3$, AAT-3 and GDH-1, are presented in Fig. 2. In $S$. squalidus, allozyme variation at

Table 1 Locations, sample sizes and collection dates of populations of Senecio spp. studied

\begin{tabular}{cllll}
\hline Location & Species & National grid reference & $N^{*}$ & Date \\
\hline Edinburgh $\dagger$ & S. vulgaris & NT268765 & $50 / 48$ & $28 / 5 / 1986$ \\
& S. cambrensis & NT268765 & 28 & $28 / 5 / 1986$ \\
& S. squalidus & NT268765 & 44 & $28 / 5 / 1986$ \\
Mochdre $\ddagger$ & S. vulgaris & SH822781 & $40 / 45$ & $3 / 10 / 1986$ \\
& S. cambrensis & SH822781 & 57 & $3 / 10 / 1986$ \\
& S. squalidus & SH818778 & 28 & $3 / 10 / 1986$ \\
Wrexham§ & & & & \\
Brymbo & S. vulgaris & SJ296539 & $21 / 38$ & $30 / 5 / 1987$ \\
& S. cambrensis & SJ296539 & 20 & $30 / 5 / 1987$ \\
Ffrith & S. vulgaris & SJ286556 & $16 / 37$ & $3 / 10 / 1986$ \\
& S. cambrensis & SJ286556 & 25 & $3 / 10 / 1986$ \\
Rhostyllen & S. vulgaris & SJ312492 & $15 / 28$ & $30 / 5 / 1987$ \\
& S. cambrensis & SJ322492 & 21 & $30 / 5 / 1987$ \\
& S. squalidus & SJ314485 & 27 & $30 / 5 / 1987$ \\
Southsea & S. vulgaris & SJ306515 & $32 / 65$ & $30 / 5 / 1987$ \\
& S. cambrensis & SJ308515 & 40 & $30 / 5 / 1987$ \\
& S. squalidus & SJ309514 & 25 & $3 / 10 / 1986$ \\
\hline
\end{tabular}

*First value for $S$. vulgaris refers to var. hibernicus, second value to var. vulgaris. †Walled embankment of river and nearby wasteground.

$\ddagger$ Roadside verge and stone wall.

$\S$ Stone walls, wasteground, roadsides and footpaths. 


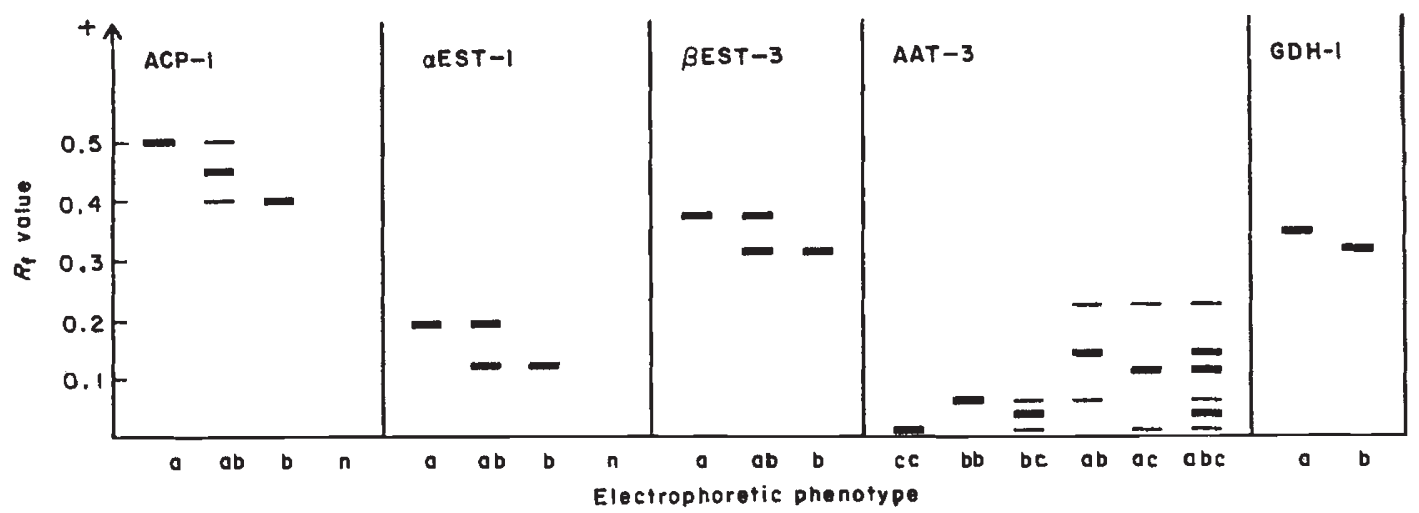

Fig. 2 Electrophoretic phenotypes resolved at polymorphic enzyme coding loci in the Senecio spp. studied. Staining intensity of bands varied in the three banded $A a t-3$ phenotypes of $S$. cambrensis reflecting gene dosage.

the Acp- 1 locus is controlled by three alleles, one of which is null (Ashton, 1990). At the Aat-3 locus, two co-dominant alleles occur, $A a t-3 b$ and $A a t-3 c$, which show disomic inheritance (Ashton, 1990). In S. vulgaris, the Aat-3 locus is duplicated and true breeding individuals exhibit one or other of three triple-banded phenotypes (Fig. 2), i.e. Aat-3ab, Aat-3ac and Aat-3bc, due to each duplicate locus being homozygous for different alleles (Abbott et al., 1992). Crosses between individuals, which differ in genotype, produce a sixbanded phenotype ( $A a t-3 a b c)$ due to heterozygosity at one of the duplicate loci. A genetic analysis of variation for esterases in S. vulgaris (Irwin, 1990), has demonstrated that allozyme variation at each of the $\alpha E s t-1$ and $\beta E s t-3$ loci results from the expression of two and three co-dominant alleles respectively: alleles at both loci show disomic inheritance. The $\beta E s t-3 a^{\prime}$ allele, identified by Irwin (1990), was absent from all material investigated in the present study except one individual of $S$. squalidus from Edinburgh of $\beta E s t-3 d a$ genotype. For the sake of simplicity this individual was viewed to exhibit the $\beta E s t-3 a$ phenotype in the present paper. At a third diallelic locus, $\beta E$ st-2 (also present in $S$. squalid$u s$ ), one allele exhibits almost complete dominance over the other in expression, and because of this, the locus was omitted from the present analysis. ,In $S$. squalidus, $\alpha$ EST-1 is not expressed; however, a third locus for $\beta \mathrm{EST}, \beta E s t-1$, is present (Irwin, 1990) but was monomorphic over all material surveyed.

Frequencies of the polymorphic electrophoretic phenotypes resolved in the populations of $S$. cambrensis, S. vulgaris (var. hibernicus and var. vulgaris) and $S$. squalidus are presented in Table 2. Data from the four populations sampled in the Wrexham area are pooled for comparison. In Wales (Mochdre and Wrexham populations), $S$. cambrensis was monomorphic for the Acp-1a and $\alpha E s t-1 a$ phenotypes, while in Edinburgh all individuals of the species exhibited the
$A c p-1 a b$ and $\alpha E s t-1 b$ phenotypes. These differences in phenotype may be explained in terms of the different parentage of $S$. cambrensis at the respective locations. At all three locations, populations of both variants of $S$. vulgaris, i.e. var. vulgaris (non-radiate) and var. hibernicus (radiate) were monomorphic for the $A c p-1 a$ phenotype. In contrast, $S$. squalidus was monomorphic for the $A c p-1 b$ phenotype at Edinburgh but polymorphic for all four $A c p-1$ phenotypes in Wales. From this, it is concluded that Edinburgh $S$. cambrensis originated from a cross between an $S$. vulgaris parent which donated the Acp-1a allele and an $S$. squalidus plant which provided the $A c p-1 b$ allele, while in Wales, the $S$. squalidus parent donated either the $a$ or null allele at the Acp-1 locus. Because $S$. squalidus does not produce an alloyzme for $\alpha E S T-1$, the phenotype for this enzyme in $S$. cambrensis is determined entirely by the $S$. vulgaris parent. Thus at Edinburgh, the $S$. vulgaris parent involved in the cross which gave rise to $S$. cambrensis must have donated the $\alpha E s t-1 b$ allele, while in Wales it will have donated the $\alpha E s t-1 a$ allele. As the radiate variant of $S$. vulgaris (var. hibernicus) in Edinburgh is monomorphic for the $\alpha E s t-1 a$ allele, the $\alpha E s t-1 b$ allele in Edinburgh $S$. cambrensis must have come from the non-radiate variant, $S$. vulgaris var. vulgaris.

The variation pattern for AAT-3 is unique among the enzymes surveyed in that it is the only locus for which different variant phenotypes of $S$. cambrensis were found at each of the Edinburgh, Mochdre and Wrexham sites. At Edinburgh, S. cambrensis exhibited a six-banded phenotype $A a t-3 a b c$. This phenotype is expected for individuals that possess three alleles at the Aat-3 locus, which is present in three copies in S. cambrensis. Plants from Edinburgh bred true for this phenotype, and it is concluded therefore that each copy of the Aat-3 locus was homozygous for a different allele, i.e. plants were fixed heterozygotes. Given that 
Table 2 Frequencies of the electrophoretic phenotypes resolved for $S$. vulgaris var. hibernicus (Svh), S. vulgaris var. vulgaris $(\mathrm{Svv}), S$. cambrensis (Sc) and $S$. squalidus (Ss) in populations at Edinburgh, Mochdre and Wrexham

\begin{tabular}{|c|c|c|c|c|c|c|c|c|c|c|c|c|}
\hline \multirow[b]{2}{*}{ Locus/phenotype } & \multicolumn{4}{|c|}{ Edinburgh } & \multicolumn{4}{|c|}{ Mochdre } & \multicolumn{4}{|c|}{ Wrexham } \\
\hline & Svh & Svv & Sc & Ss & Svh & Svv & Sc & Ss & Svh & Svv & Sc & Ss \\
\hline$n$ & 50 & 48 & 28 & 44 & 40 & 45 & 57 & 26 & 84 & 168 & 106 & 85 \\
\hline \multicolumn{13}{|l|}{ Acp-1 } \\
\hline $\mathrm{a}$ & 1.0 & 1.0 & - & - & 1.0 & 1.0 & 1.0 & 0.29 & 1.0 & 1.0 & 1.0 & 0.25 \\
\hline$a b$ & - & - & 1.0 & - & - & - & - & 0.35 & - & - & - & 0.33 \\
\hline $\mathrm{b}$ & - & - & - & 1.0 & - & - & - & 0.29 & - & - & - & 0.38 \\
\hline nn & - & - & - & - & - & - & - & 0.07 & - & - & - & 0.04 \\
\hline \multicolumn{13}{|l|}{$\alpha$ Est-1 } \\
\hline a & 1.0 & 0.63 & - & - & 1.0 & 0.62 & 1.0 & - & 0.97 & 0.73 & 1.0 & - \\
\hline $\mathrm{ab}$ & - & 0.04 & - & - & - & - & - & - & 0.01 & 0.02 & - & - \\
\hline $\mathrm{b}$ & - & 0.33 & 1.0 & - & - & 0.38 & - & - & 0.02 & 0.25 & - & - \\
\hline \multicolumn{13}{|l|}{$\beta$ Est-3 } \\
\hline a & - & 0.22 & - & 0.84 & 0.63 & - & 0.07 & 0.81 & 0.01 & 0.01 & 0.01 & 0.93 \\
\hline $\mathrm{ab}$ & 0.02 & - & 1.0 & 0.16 & 0.02 & - & 0.56 & 0.19 & - & - & 0.12 & 0.07 \\
\hline $\mathrm{b}$ & 0.98 & 0.78 & - & - & 0.35 & 1.0 & 0.37 & - & 0.99 & 0.99 & 0.87 & - \\
\hline \multicolumn{13}{|l|}{ Gdh-1 } \\
\hline $\begin{array}{l}\mathrm{a} \\
\mathrm{b}\end{array}$ & - & - & - & 1.0 & - & - & - & 1.0 & - & -10 & -10 & 1.0 \\
\hline b & 1.0 & 1.0 & 1.0 & - & 1.0 & 1.0 & 1.0 & - & 1.0 & 1.0 & 1.0 & - \\
\hline$n$ & 25 & 27 & 28 & 44 & 24 & 20 & 34 & 26 & 76 & 115 & 89 & 85 \\
\hline \multicolumn{13}{|l|}{ Aat-3 } \\
\hline $\begin{array}{l}a b c \\
a b\end{array}$ & - & - & 1.0 & - & - & - & - & - & $\begin{array}{r}0.03 \\
0.33\end{array}$ & 0.03 & -0.12 & - \\
\hline $\begin{array}{l}\mathrm{ab} \\
\mathrm{ac}\end{array}$ & $\begin{array}{l}0.28 \\
0.08\end{array}$ & 0.92 & - & - & $\begin{array}{l}0.08 \\
0.88\end{array}$ & 1.0 & $\begin{array}{r}1.0 \\
-\end{array}$ & - & $\begin{array}{l}0.33 \\
0.33\end{array}$ & $\begin{array}{l}0.93 \\
0.01\end{array}$ & 0.88 & - \\
\hline $\mathrm{bc}$ & $\begin{array}{l}0.08 \\
0.64\end{array}$ & $\begin{array}{l}0.04 \\
0.04\end{array}$ & - & -0.25 & $\begin{array}{l}0.88 \\
0.04\end{array}$ & - & $\overline{-}$ & 0.31 & $\begin{array}{l}0.33 \\
0.31\end{array}$ & $\begin{array}{l}0.01 \\
0.03\end{array}$ & - & $-\overline{0.15}$ \\
\hline $\mathrm{bb}$ & $\begin{array}{l}0.64 \\
-\end{array}$ & $\begin{array}{l}0.04 \\
-\end{array}$ & $\overline{-}$ & 0.02 & - & - & - & 0.27 & - & - & - & $\begin{array}{l}0.15 \\
0.08\end{array}$ \\
\hline $\mathrm{cc}$ & - & - & - & 0.73 & - & - & - & 0.42 & - & - & - & 0.77 \\
\hline
\end{tabular}

$n=$ the number of individuals scored for an enzyme system.

one parent of $S$. cambrensis at Edinburgh was $S$. vulgaris var. vulgaris (based on the aEST-1 evidence mentioned above), it is likely that $S$. cambrensis originated in Edinburgh from a cross between an $S$. vulgaris individual of genotype $A a t-3 a a / b b$ and an $S$. squalidus plant which donated the $A a t-3 c$ allele. In the Wrexham area, the six-banded phenotype was also recorded in $S$. cambrensis but at a low frequency. Much more common here was the Aat-3ac triple banded phenotype. In contrast, at Mochdre, S. cambrensis was monomorphic for the triple-banded $A a t-3 a b$ phenotype.

The occurrence of three different Aat-3 phenotypes in Welsh $S$. cambrensis may be explained in either of two ways. First, it is possible that all plants in Wales originally exhibited the six-banded Aat-3abc phenotype, due to an origin similar to that postulated for Edinburgh $S$. cambrensis. However, following pairing between homoeologous chromosomes, this phenotype has segregated for a range of $A a t-3$ phenotypes. Due to founder effects or selection, one segregant, Aat-3ac, has survived in the Wrexham area, together with the six-banded phenotype, while another, Aat-3b, founded the Mochdre population. An alternative explanation is that each Aat-3 phenotype in Wales is the product of an independent origin of $S$. cambrensis. It is feasible that at Mochdre, $S$. cambrensis arose following local hybridization bertween an $S$. vulgaris individual exhibiting the triple-banded Aat-3ab phenotype (the only phenotype found among plants of non-radiate $S$. vulgaris var. vulgaris surveyed at Mochdre) and an $S$. squalidus individual which donated the $A a t-3 b$ allele. This would have yielded the $A a t-3 a b$ phenotype for which the population of $S$. cambrensis at Mochdre is monomorphic. In contrast, the 
Aat-3ac triple-banded phenotype, which is common in the Wrexham area, could be the product of hybridization between an $S$. vulgaris individual with the Aat-3ac phenotype (common in var. hibernicus at Wrexham) and an $S$. squalidus plant which donated the Aat-3c allele. Finally, the less-frequent six-banded $A a t-3 a b c$ phenotype in Wrexham $S$. cambrensis would have been derived in the way already suggested.

Multivalents are occasionally observed in metaphase 1 cells of $S$. cambrensis (Ingram \& Noltie, 1984, 1987) and thus it is feasible that the two triple-banded Aat-3 phenotypes recorded in Welsh $S$. cambrensis could have arisen by segregation from the six-banded Aat-3 phenotype following pairing between homoeologous chromosomes carrying copies of the Aat-3 locus (rather than by separate hybridization events). Ingram \& Noltie (1984) have proposed that homoeologous pairing was responsible for the generation of a polymorphism for capitulum type recorded in both Welsh and Edinburgh populations of $S$. cambrensis. In the present study, segregation following homoeologous pairing would also account for the pattern of variation resolved for $\beta$ EST-3. Whereas $S$. cambrensis was monomorphic at Edinburgh for the $\beta E s t-3 a b$ phenotype (indicating fixed heterozygosity), the species was polymorphic at Mochdre and in the Wrexham area, exhibiting two single-banded phenotypes $(\beta E s t-3 a$ and $\beta E s t-3 b)$ as well as the double-banded phenotype. At Edinburgh, S. cambrensis most probably originated from a cross between $S$. vulgaris, which donated the $\beta E s t-3 b$ allele, and $S$. squalidus, which provided the $\beta E s t-3 a$ allele, these being the most common alleles in the respective parents. The origin of Welsh $S$. cambrensis most probably also involved a cross between these two parental types but following homoeologous chromosome pairing and segregation from the fixed heterozygote, the two single-banded $\beta E s t-3$ variants have been generated.

To sum up, therefore, the electrophoretic variation resolved at the $A c p-1$ and $\alpha E s t-1$ loci provides strong evidence of separate origins of $S$. cambrensis in Wales and in Edinburgh. Furthermore, the variation which occurs for AAT-3 in Welsh populations may be explained in terms of either two additional origins of $S$. cambrensis in Wales or as a result of segregation from a fixed heterozygote of $A a t-3 a b c$ phenotype. Such segregation, which follows from homoeologous chromosome pairing in a fixed heterozygote, would also explain the variation present in Welsh populations for $\beta$ EST-3. In this respect, it is of interest that while Edinburgh $S$. cambrensis has remained monomorphic for the $\beta E s t-$ $3 a b$ phenotype, both Welsh populations are polymorphic. This difference may reflect the shorter period of time for variation to have been generated in the
Edinburgh population, although in view of its small size (see below), any new variants generated by homoeologous pairing may have been quickly lost from the Edinburgh population through drift. Previous studies of genetic diversity in newly arisen allopolyploids have indicated that pairing between homoeologous chromosomes has been instrumental in releasing genetic variation in Tragopogon mirus and T. miscellus (Roose \& Gottlieb, 1976), but not in Spartina anglica (Raybould et al., 1991a, b).

One odd result to emerge from the electrophoretic survey was that for GDH-1. For this enzyme both $S$. vulgaris and $S$. cambrensis were monomorphic for the $G d h-1 b$ phenotype over all populations surveyed, while $S$. squalidus was monomorphic for $G d h-1 a$. Thus $S$. cambrensis did not exhibit the expected additive phenotype. It is feasible that in all three populations, $S$. cambrensis initially produced both GDH-1 allozymes; however, the allele encoding the GDH-1a allozyme has since been silenced, or lost, following homoeologous chromosome pairing and the generation of the $G d h-1 b$ phenotype. Neither of these explanations seems reasonable, however, as gene silencing is unlikely to have occurred in a newly arisen allopolyploid and loss of the $G d h-1 a$ allele in all three populations following homoeologous pairing would be unexpected. Instead, it is possible that $S$. cambrensis only ever expressed one form of GDH, the GDH-1a allozyme. The stain used to resolve $\mathrm{GDH}$ detects enzymes that are $\mathrm{NAD}^{+}$dependent, i.e. GDH enzymes which are associated with the mitochondria (Stewart et al., 1980). Such enzymes in Senecio are, nonetheless, probably encoded by genes in the nucleus, as Pryor (1974) has shown that in maize there is Mendelian rather than maternal inheritance of GDH variants. The occurrence of the same banding pattern for GDH-1 in S. cambrensis and $S$. vulgaris, therefore, could be due to a form of modification of activity under the control of conditions in the mitochondria. As the proposed origin of $S$. cambrensis postulates that $S$. vulgaris was the female parent (Weir \& Ingram, 1980), the mitochondrial genome of $S$. cam brensis would be expected to have been inherited from $S$. vulgaris and, therefore, may exert the same form of control on GDH expression as in S. vulgaris.

For no enzyme system surveyed was an additional allozyme found in S. cambrensis which was not present in one of the respective parents. This situation contrasts with that found by Roose \& Gottlieb (1976) in the newly arisen species Tragopogon mirus and $T$. miscellus, and also the presence of one unique isozyme found by Raybould et al. (1991a) in Spartina anglica. Roose \& Gottlieb (1976) considered that the presence of two divergent genomes in an allopolyploid would enable the production of all the enzymes produced by 
the respective parents as well as some additional novel enzymes. This they suggested might be important in the establishment of an allopolyploid, allowing it to develop over a broader range of environments than either parent. Whether the successful establishment of $S$. cambrensis in Britain is hampered by the lack of additional unique enzymes relative to the parental species remains to be determined. Clearly more enzyme systems for which the parents are divergent need to be analysed.

In the area around Wrexham in Wales, $S$. cambrensis is now firmly established (Ingram \& Noltie, 1991). The species also appears to be well established at Mochdre, although the nature of the site (a roadside verge) suggests that its survival may be threatened in the future. Far less secure is the future of the species in Edinburgh. At the time of its discovery in Edinburgh in 1982, the species was recorded at six sites within an area of $4 \mathrm{~km}^{2}$ and more than 100 individuals were counted. In 1989 the species remained at only two of these sites with a total of five individuals recorded. The decline in number of individuals in the Leith area of Edinburgh has run parallel with a reduction in wastesites and building plots on which $S$. cambrensis occurs.

Even if the Edinburgh population should become extinct in the near future, it is possible that new origins of $S$. cambrensis will occur elsewhere in Britain in future years. Examples of the triploid hybrid $S$. vulgaris $\times S$. squalidus, verified by cytological analysis, have been reported from various British locations where the allopolyploid has yet to be found (Stace, 1977; Brettell \& Leslie, 1978). Clearly there is the potential for further independent origins of $S$. cambrensis in Britain.

The occurrence of at least two independent origins of $S$. cambrensis in Britain, as demonstrated by the present study, provides further evidence that multiple origins of polyploid species may be a common phenomenon in the plant kingdom. This mode of origin for allopolyploids has been documented previously for the angiosperms Tragopogon mirus and T. miscellus (Roose \& Gottlieb, 1976; Soltis \& Soltis, 1989), the pteridophytes Asplenium bradleyi D. C. Eaton and $A$. pinnatifidium Nutt. (Werth et al., 1985) and the bryophyte Plagiomnium medium (Br. Eur.) Kop. (Wyatt et al., 1988). There is also recent evidence that autopolyploids of the angiosperm Heuchera micrantha Dougl. (Soltis et al., 1989) originated in a multiple way. Polyploids that arise in this way will sample at each site of origin, sets of parental genes which have already been subject to selection for local conditions. As a consequence, the potential for successful colonization and establishment is likely to be enhanced.

\section{Acknowledgements}

The research was conducted while PAA was in receipt of a postgraduate research studentship funded by NERC. We gratefully acknowledge the excellent technical assistance provided by David Forbes.

\section{References}

ABBOTT, R. J., ASHTON, P. A. AND FORBES, D. G. 1992. Introgressive origin of the radiate groundsel, Senecio vulgaris L. var hibernicus Syme: AAT-3 evidence. Heredity, (in press).

Ashton, P. A. 1990. Multiple Origins of Senecio cambrensis Rosser, and Related Evolutionary Studies in British Senecio. Ph.D. Thesis, University of St Andrews.

BRUMMITT, J. M. 1971. In plant records. Watsonia, 8, 408. BRETTELL, R. I. S. AND LESLIE, A. C. 1978. Senecio squalidus L. $\times$ S. vulgaris L. in Cambridgeshire. Watsonia, 12, 155 . CRISP, P. C. 1972. Cytotaxonomic Studies in the Section Annui of Senecio. Unpublished Ph.D. Thesis, University of London.

HUSKINS, C. L. 1931. The origin of Spartina townsendii. Genetica, 12, 531-538.

INGRAM, R. AND NOLTIE, H. J. 1984. Ray floret morphology and the origin of variability in Senecio cambrensis Rosser, a recently established allopolyploid species. New Phytol., 96, 601-607.

INGRAM, R. AND NOLTIE, H. J. 1987. The control of chiasma frequency within a polyploid series in the genus Senecio (Compositae). Genetica, 72, 37-41.

INGRAM, R. AND NOLTIE, H. J. 1992. Biological Flora of the British Isles. Senecio cambrensis Rosser. J. Ecol. (in press).

INGRAM, R., WEIR, J. AND ABBOTT, R. J. 1980. New evidence concerning the origin of inland radiate groundsel, Senecio vulgaris L. var. hibernicus Syme. New Phytol., 84, 543-546.

IR WIN, J. A. 1990. Male Competition and Outcrossing Rate in a Hermaphrodite Plant. Ph.D. Thesis, University of St Andrews.

KENT, D. H. 1955. Scottish records of Senecio squalidus L. Proc. Bot. Soc. Brit. Is., 1, 312-313.

KENT, D. H. 1956. Senecio squalidus L. in the British Isles. I. Early records (to 1877). Proc. Bot. Soc. Brit. Is., 2, 115-118.

KENT, D. H. 1963. Senecio squalidus L. in the British Isles. 7. Wales. Nature in Wales, 8, 175-178.

LEWIS, W. H. 1980 . Polyploidy in angiosperms: Dicotyledons. In: Lewis, W. H. (ed) Polyploidy: Biological Relevance. Plenum, New York, pp. 241-268.

MARCHANT, C. J. 1963. Corrected chromosome numbers for Spartina $\times$ townsendii and its parent species. Nature, 199, 929.

MARChaNT, C. J. 1967. Evolution in Spartina (Gramineae). I. History and morphology of the genus in Britain. J. Linn. Soc. (Bot.), 60, 1-24.

MARCHANT, C. J. 1968. Evolution in Spartina (Gramineae). II. Chromosomes, basic relationships and the problem of the S. $\times$ townsendii agg. J. Linn. Soc. (Bot.), 60, 381-409. 
MARSHALL, D. F. AND ABBOTT, R. J. 1980. On the frequency of introgression of the radiate $\left(T_{\mathrm{r}}\right)$ allele from Senecio squalidus into Senecio vulgaris L. Heredity, 45, 133-135. owNBEY, M. 1950. Natural hybridization and amphiploidy in the genus Tragopogon. Am. J. Bot., 37, 487-499.

PRYOR, A. J. 1974. Allelic glutamic dehydrogenase isozymes in maize - single hybrid isozyme in heterozygotes. Heredity, 32, 397-419.

RAYBOULD, A. F., GRAY, A. J., LAWRENCE, M. J. AND MARSHALL, D. F. 1991a. The evolution of Spartina anglica C. E. Hubbard (Gramineae): Origin and genetic variability. Biol. J. Linn. Soc. 43, 111-126.

RAYBOULD, A. F., GRAY, A. J., LAWRENCE, M. J. AND MARSHALL, D. F. 1991b. The evolution of Spartina anglica C. E. Hubbard (Gramineae): Genetic variation and status of the parental species in Britain. Biol. J. Linn. Soc. (in press).

ROOSE, M. L. AND GOTTLIEB, L. D. 1976. Genetic and biochemical consequences of polyploidy in Tragopogon. Evolution, 30 , 818-830.

ROSSER, E. M. 1955. A new British species of Senecio. Watsonia, 3, 228-232.

SOLTIS, D. E. AND SOLTIS, P. S. 1989. Allopolyploid speciation in Tragopogon: Insights from chloroplast DNA. Am. J. Bot., 76, 1119-1124.
SOLTIS, D. E., SOLTTS, P. S. AND NESS, B. D. 1989. Chloroplast-DNA variation and multiple origins of autopolyploidy in Heuchera micrantha (Saxifragaceae). Evolution, 43, 650-656.

STACE, C. A. 1977. The origin of radiate Senecio vulgaris $\mathbf{L}$. Heredity, 39, 383-388.

STACE, C. A. 1987. Hybridization and the plant species. In: Urbanska, K. M. (ed.) Differentiation Patterns in Higher Plants, Academic Press, London, pp. 115-127.

STEWART, G. R., MANN, A. F. AND FENTEM, P. A. 1980. Enzymes of glutamate formation: glutamate dehydrogenase, glutamine synthetase, and glutamine synthase. In: Miflin, B. J. (ed.) The Biochemistry of Plants, Vol. 5, Amino Acids and Derivatives, Academic Press, London, pp. 271-327.

WEIR, J. AND INGRAM, R. 1980. Ray morphology and cytological investigations of Senecio cambrensis Rosser. New Phytol., 86, 237-241.

WERTH, C. R., GUTTMAN, S. I. AND ESHBAUGH, W. H. 1985. Recurring origins of allopolyploid species in Asplenium. Science, 228, 731-733.

WYATT, R., ODRZYKOSKI, I. J., STONEBURNER, A., BASS, H. W. AND GALAU, G. A. 1988. Allopolyploidy in bryophytes: multiple origins of Plagiomnium medium. Proc. Nat. Acad. Sci., USA, 85, 5601-5604. 